ASLI QoL 2017
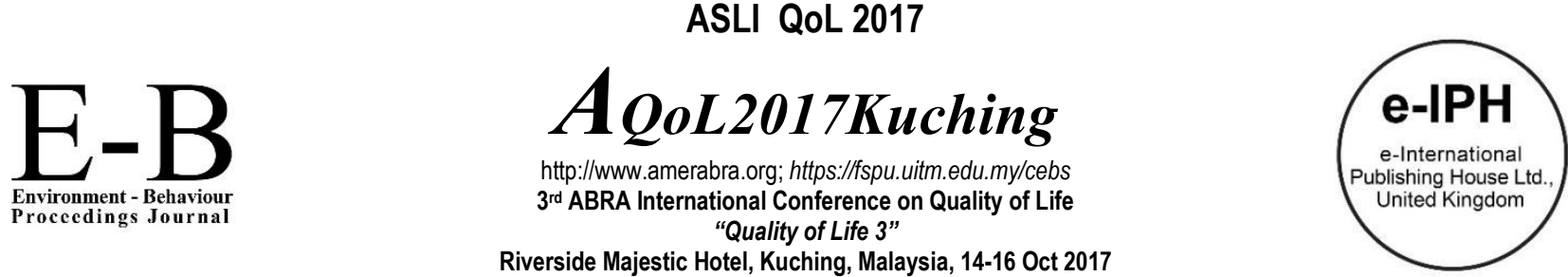

\title{
The Impact of Flood Disaster on Daily Activities and Quality of Life amongst Women Flood Disaster Survivors
}

\author{
Ahmad Zaidin Othmann ${ }^{1,2}$, Akehsan Dahlan'1, Suleiman Murad ${ }^{1}$ \\ 1Department of Occupational Therapy, Faculty of Health Sciences, Universiti Teknologi MARA (UiTM) Selangor, Puncak Alam Campus, Malaysia \\ 2School of Occupational Therapy, Perdana University, Serdang, Malaysia \\ ahmadzaidin91@ymail.com
}

\begin{abstract}
Flood disaster disrupted routine and performance in daily activities. Disengagement from performing daily activities have a negative impact on health leading to decrease the quality of life. Women were tied with the social norms of having to take care of others, which proves to be harder to juggle in times of disaster. The objective of this study was to identify the most affected occupations among the sandwich generation of women flood survivors. One hundred and thirty-one participants participated in this cross-sectional study. The results indicated that there is a significant difference in rest and sleep among the sandwich generation of women flood survivors.
\end{abstract}

Keywords: Flood disaster; Daily Activities; Occupations; Quality of Life

eISSN: 2398-4287@ 2017. The Authors. Published for AMER ABRA by e-International Publishing House, Ltd., UK. This is an open access article under the CC BYNCND license (http://creativecommons.org/licenses/by-nc-nd/4.0). Peer-review under responsibility of AMER (Association of Malaysian Environment-Behaviour Researchers), ABRA (Association of Behavioural Researchers on Asians) and cE-Bs (Centre for Environment-Behaviour Studies), Faculty of Architecture, Planning \& Surveying, Universiti Teknologi MARA, Malaysia.

https://doi.org/10.21834/e-bpj.v2i6.944

\subsection{Introduction}

Flood disaster has become a more frequent natural disaster occurring in Malaysia that is affecting millions of people and inflicting millions in monetary values every year (Mohit \& Sellu, 2013). Data from Akasah and Doraisamy (2015), found that the 2014 flood affecting the whole peninsular of Malaysia had caused monetary damage of RM 337.6 million and had caused almost 60,000 survivors to be evacuated to a relief centre. It is imperative that a community would be able to rebuild their life after disaster quickly or it will hurt the economy exorbitantly. Thus, it is helpful that the community can recover themselves from a disaster quickly by having strong resilience and their basic needs are met, so they would be able to be the aide in helping the government to build the local community and the economy back to its feet.

Basic needs can comprise of the providence of necessities and engagement in normal routine or daily activities. Daily activities is comprise of 8 components which are: (1) activities of daily living (ADLs; activities that is oriented towards taking care of one's own body such as bathing, eating, and personal hygiene), (2) instrumental activities of daily living (IADLs; activities that support daily life that is more complex than ADL such as home maintenance, care of others, and health management), (3) rest and sleep, (4) education, (5) work, (6) play, (7) leisure, and (8) social participation (American Occupational Therapy Association [AOTA], 2014). According to Baker (2012), daily activities can be defined as meaningful and purposeful activities a person does that provides a sense of healing and relief, in which, disengagement would affect the physical and mental health. Flood survivors' routines are changing and being unable to perform daily activities would cause them to do more in other parts of daily activities. For example, a disaster victim may not have enough sleep during a flood, but their IADLs, which comprises of cleaning the house and care of family members, are

eISSN: 2398-4287@ 2017. The Authors. Published for AMER ABRA by e-International Publishing House, Ltd., UK. This is an open access article under the CC BYNCND license (http://creativecommons.org/licenses/by-nc-nd/4.0/). Peer-review under responsibility of AMER (Association of Malaysian Environment-Behaviour Researchers), ABRA (Association of Behavioural Researchers on Asians) and cE-Bs (Centre for Environment-Behaviour Studies), Faculty of Architecture, Planning \& Surveying, Universiti Teknologi MARA, Malaysia.

https://doi.org/10.21834/e-bpj.v2i6.944 
over-occupied. This imbalance and deprivation would affect a person's well-being as daily activities are what motivates a person to face a new day. Being denied of their rights to perform their regular daily activities is an injustice that would affect a person's health and quality of life (Townsend \& Whiteford, 2005).

\subsection{Literature Review}

Victims who have been experiencing flood disaster regularly every year had been developing stress and anxiety, especially after a long period of heavy rain, which would affect their quality of life (Abdullah et al., 2015). This emotion if not controlled well, will cause its victims to developed posttraumatic stress disorder (PTSD). Heshmati et al., (2010), stated that PTSD is a psychiatric disorder that as a result of a person's experiencing one or more traumatic events in their life, causing exhibition of a countless number of symptoms. Ahmadizadeh et al. (2010), further describe this symptom as intrusive thoughts, nightmares, and flashbacks of past traumatic events, avoidance of reminders of the trauma, hypervigilance and sleep disturbance. PTSD which can have lasting effects on its survivors can also cause a decrease in quality of life (Zokaeefar et al., 2015).

Women were specifically chosen in this study as they are considered as vulnerable populations during a disaster. Gender is defined as what is expected of, allowed to, and valued on a woman or man in a given context (United Nations Development Programme [UNDP], 2010). According to UNDP (2010), the opportunities, responsibilities, resources, and power among women and men are constructed socially which is context-specific, time-specific, and changeable. Thus, gender does not only point to being a male or female only but also, what is expected of the role for both the gender in performing out their duty or activity in a construct of the local community. Every country would have different roles and expectations for woman and man. However, women are often put in a disadvantaged position in both developing and developed countries, in which, gender equalities focuses on women's empowerment (UNDP, 2010). According to Neumayer and Plumper (2007), women are vulnerable to disasters due to the existent gender gap and inequality. Factors that influence the vulnerability of women to disasters are due to their biological and physiological differences, social norms and role behaviours, and socioeconomic factors (Neumayer \& Plumper, 2007). In flood events in Manila, Philippines, women were having more emotional and psychological burden as they are expected to be responsible for taking care of the children and elderly, which adds up to the workload of maintaining the home and making a living (Reyes \& Lu, 2015). Similar matters happened to women in Nigeria where they are expected to take care of the house, family, and nutrition (Ajibade, McBean \& Bezner-Kerr, 2013). An interesting factor with regards to activities of daily living would be personal hygiene among women, where Ajibade et al., (2013), mentioned that women are more exposed to urinary tract infections as there is lack of sanitation, clean water (for bathing and personal female hygiene) and privacy after a flood.

Though there are several problems (physical, economic, psychological and special needs populations) due to a disaster, not much emphasis is given to the effect of a disaster on engagement in daily activities of these survivors. It is known that flood and other disasters would disrupt the transportation system, electrical, sanitation, and water system, which is a basic need for everyone. This may somehow affect their daily living performance, which would affect the recovery period after a disaster. Disaster gives an impact to a person's psychological function and normal routine, it also affects a person's quality of life, which represents how a person feels and perceives his life would be especially after a disaster. So far, few studies have been done on the effect of the disaster on occupation engagement. Hence, the aim of this study was to determine the impact of the flood disaster on the engagement of daily activities among women flood survivors after they have returned home from a sheltered environment. The objective of the study is to identify the most affected occupations among the sandwich generation (middle age) of women flood survivors.

\subsection{Research Gap}

According to Srivastava, David and Ramakrishnan (2006), disaster gives a huge impact on the physical, psychological, social, and economics of the survivors. Many focus was given in mental health during a disaster. However, there are existing knowledge regarding how normal pattern, routine, and occupations among disaster survivors will lead to improved wellbeing of the survivors. Occupations and normal engagement in daily routine was found to be therapeutic for the survivors, as it helps them to cope with the situations in engaging to something that they are familiar with (Rosenfeld, 1989; Fine, 1991; Stone, 2006). The available literature agrees on the impact of a disaster on survivors' occupations. Most of the studies (Oakley, Creswell \& Park, 2008; Scaffa et al., 2009; Riggers, 2011) highlighted that, the survivors' quality of life is low due to the fact that they are not able to engage in meaningful occupations.

However, so far, less literature have pointed out which part of the occupation as outlined in the OTPF 3rd Edition (AOTA, 2014) was affected the most or least. This is important as different cultures and geographical backgrounds value occupations differently. Clear data on which occupations are affected, will provide an insight and guide related agencies in times of a disaster, hence, improving resilience among survivors and allowing them to rebuild themselves after a disaster quicker.

Since most of the literature does not address which occupations were affected and how severe the occupations were affected due to a flood disaster, these serve as gap for this study.

\subsection{Methodology}

\subsection{Settings and participants}


The study was conducted in Kuala Selangor, Malaysia, consisting of women, aged 18 years old and above, and have had experienced the recent flood disaster of not more than one year.

\subsection{Sampling}

Purposive sampling method was used in this study, for participants with specific criteria was chosen. Among the criteria for the participants are: (1) women, (2) minimum age of 18 years old, (3) experiencing riverine flood, (4) able to read, (5) scored low (below 16) in level of depression on the Beck Depression Inventory (Malay version), (6) scored below 17 in Malay Mini-Mental State Examination signifying normal cognitive functioning, and (7) experience flood within 1 year.

There was a total of 131 participants in this study. All of the participants who were willing to participate in the program and fit into the inclusion criteria were chosen. Data had been collected through self-administration of the questionnaire, by the survivors.

\subsection{Research instruments}

The Impact of Flood on Occupations (I-FLOAT) questionnaire was specifically developed for this study. It had undergone three stages of questionnaire development to find out the impact of the flood disaster on daily activities of the survivors. The first stage involved the interview process with three survivors, regarding their difficulties in engaging in daily activities after they went back home from flood evacuation centres, as well as a rating scale for the questionnaire that is easily understood by the survivors. The survivors' opinion was then brought to five experts, for further discussion and clarifications regarding the questionnaire. The experts have agreed that the problems faced by the survivors fit into the domains of occupations from Occupational Therapy Practice Framework (OTPF) 3rd Edition (AOTA, 2014). Thus, the domain in the questionnaire is adopted from the OTPF 3rd edition. The rating and scoring were based on the numerical rating scale (NRS) and visual rating scale (VRS) of pain scale, and the interpretation of the results was based on the formula in Activities of Daily Living Questionnaire (ADLQ). Afterwards, the questionnaire was printed out based on the suggestions and opinions by both the experts and survivors, to be piloted among ten flood disaster survivors, to gain their insights of the questionnaire (whether it is understandable and easy to rate or not), before the real study was being conducted. The third and final stage was the test-retest reliability to determine the level of agreement, level of correlations and relatedness of the answer provided by the participants' overtime (Time 1 and Time 2). The test-retest reliability analysis indicates that there is medium and large correlation between base line (Time 1) and re-test (time 2) ranging from 0.60 to 0.90 , while there is range between moderate and excellent reliability and relatedness of the responses at two times between the base line (Time 1) and re-test (time 2). The highest reliability is in the rest/sleep area $(I C C=0.90)$ while the lowest reliability is in the area of work $(0.60)$ as shown in table 3.15 . Kappa value cannot be computed as the statistics require a symmetric 2-way table in which the values of the first variable match the values of the second variable. The data obtained is a ratio type of data which range from 1 to 10 and unlike the ordinal type of data that have four or five level of measurement, e.g. strongly agree $=1$, agree $=2$, etc. which suitable for kappa analysis. The results indicate that the Impact of Flood Disaster on Occupations (I-Float) questionnaires have a good test-retest reliability.

\subsection{Ethics}

The study was approved by the Research Ethics Committee of Universiti Teknologi MARA. All participants were explained the aim and objectives of the study and informed consent were obtained and collected from the participants.

\subsection{Study Design}

The cross-sectional study design will be used in finding out the most affected occupations among the sandwich generation of women flood disaster survivors where the relationship between engagement in daily activities among flood survivors and demographic variables will be explored and compared. A cross-sectional design was chosen as this study was carried out over a short period. Furthermore, data were collected directly based on individual characteristics that met the inclusion and exclusion criteria.

\subsection{Data Analysis}

Data were analysed using the Statistical Package for the Social Sciences (SPSS) version 21.0. SPSS was used to process and analyse the data from the questionnaire that include respondent's demographic data and score from I-FLOAT. Descriptive analysis was used to determine the frequency, percentages, median and interquartile range (IQR) of the socio-demographic data and the score of I-FLOAT. Inferential analysis of the study used the Kruskal-Wallis Test (more than two groups) and Mann-Whitney U Test (between 2 groups) to compare the demographic data (include age, gender, ethnic and flood experience or history) with the I-FLOAT scores. It was then followed by posthoc analysis of the results for multiple comparisons.

\subsection{Results and Discussions}

\subsection{Demographic Information}

Basic demographic information (age group, number of health problems, ethnicity, marital status, number of children, number of people living together, educational background, and total number of floods experienced) are presented in Table 1. There are a total of 131 participants that met the inclusion and exclusion criteria of the study. 
Table 1. Socio-demographic characteristics of the participants

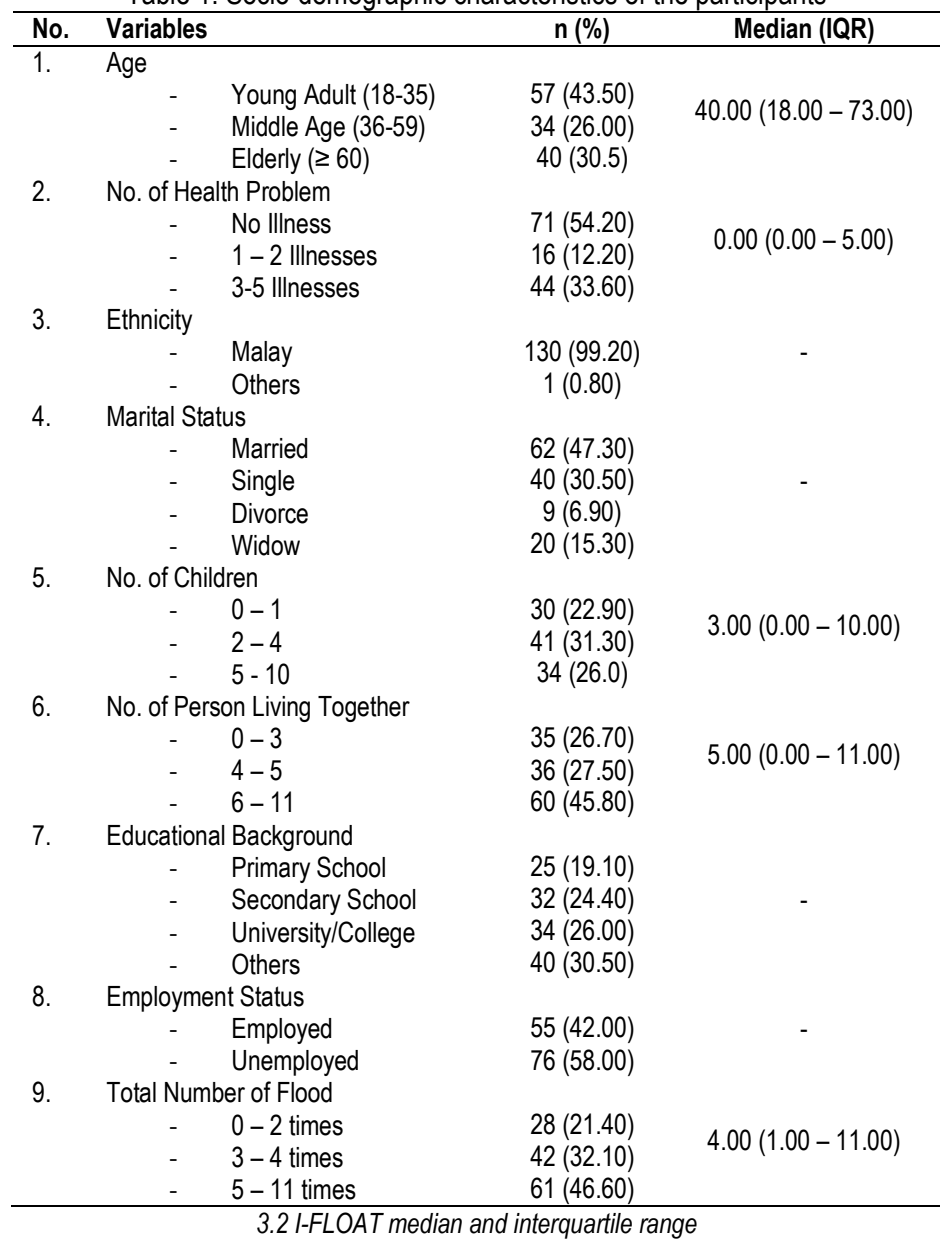

Descriptive analysis for the median and interquartile range had been established for each domain of I-FLOAT (ADLs, IADLs, Rest and Sleep, Education, Work, Play, Leisure, and Social Participation) as shown in table 2. Daily activities that were found to be the most affected among women flood disaster survivors are $\mathrm{ADL}$ (median $=7.00 ; \mathrm{IQR}=0.00-10.00$ ), IADL (median $=7.00 ; \mathrm{IQR}=0.00$ -10.00 ), and work (median $=7.00 ; I Q R=0.00-10.00$ ), followed by Education (median $=6.00 ; I Q R=0.00-10.00$ ), Social Participation (median $=6.00 ; \mathrm{IQR}=0.00-10.00$ ), Play (median $=5.00 ; \mathrm{IQR}=0.00-10.00)$, Leisure (median $=5.00 ; \mathrm{IQR}=0.00-$ 10.00 ), and the least affected was Rest and Sleep (median $=4.00 ; I Q R=0.00-10.00)$. The overall level of difficulty in engaging in daily activities among the survivors were of moderate level of difficulty (median $=58.33$; IQR $=0.00-92.86$ ).

Table 2. Descriptive analysis of I-FLOAT questionnaire domains

\begin{tabular}{|c|c|c|c|}
\hline No. & Variables & $\mathrm{n}(\%)$ & Median (IQR) \\
\hline \multirow[t]{5}{*}{1.} & $\operatorname{ADL}(N=131)$ & & \multirow{5}{*}{$7.00(0.00-10.00)$} \\
\hline & - $\quad$ No difficulty (0) & $4(3.10)$ & \\
\hline & Mild Difficulty (1-3) & $9(6.90)$ & \\
\hline & Moderate Difficulty (4-6) & $41(31.30)$ & \\
\hline & Severe Difficulty $(7-10)$ & $77(58.80)$ & \\
\hline \multirow[t]{5}{*}{2.} & IADL (N=131) & & \\
\hline & - $\quad$ No difficulty (0) & $4(3.10)$ & \multirow{4}{*}{$7.00(0.00-10.00)$} \\
\hline & Mild Difficulty (1-3) & $9(6.90)$ & \\
\hline & Moderate Difficulty (4-6) & $35(26.70)$ & \\
\hline & - $\quad$ Severe Difficulty $(7-10)$ & $83(63.40)$ & \\
\hline \multirow[t]{5}{*}{3.} & Rest \& Sleep $(N=131)$ & & \multirow{5}{*}{$4.00(0.00-10.00)$} \\
\hline & - $\quad$ No difficulty $(0)$ & $8(6.10)$ & \\
\hline & Mild Difficulty (1-3) & $9(6.90)$ & \\
\hline & Moderate Difficulty (4-6) & $92(70.20)$ & \\
\hline & - $\quad$ Severe Difficulty $(7-10)^{\prime}$ & $22(16.80)$ & \\
\hline \multirow[t]{5}{*}{4.} & Education $(\mathrm{N}=56)$ & & \\
\hline & - $\quad$ No difficulty $(0)$ & $10(17.90)$ & \multirow{4}{*}{$6.00(0.00-10.00)$} \\
\hline & Mild Difficulty (1-3) & $4(7.10)$ & \\
\hline & Moderate Difficulty (4-6) & $23(41.10)$ & \\
\hline & Severe Difficulty $(7-10)$ & $19(33.90)$ & \\
\hline 5. & Work $(\mathrm{N}=48)$ & $7(1190$ & $7.00(0.00-10.00)$ \\
\hline
\end{tabular}




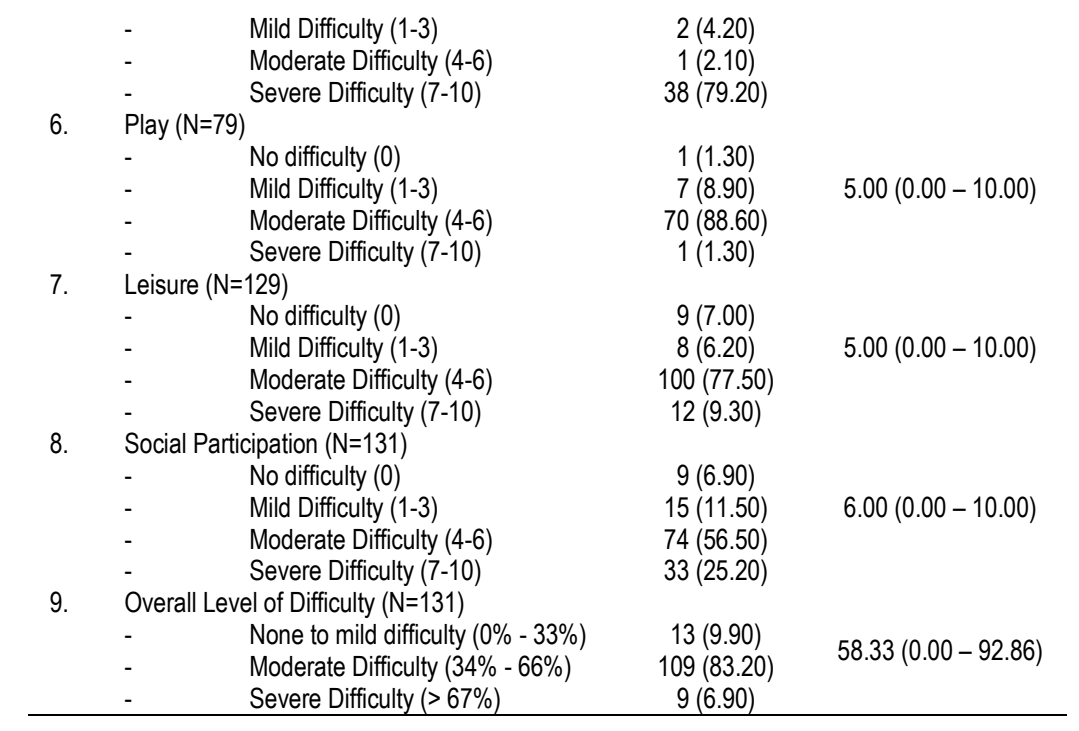

\subsubsection{Discussion on I-FLOAT median and interquartile range}

Findings showed that rest and sleep are the least affected daily activities among the flood disaster survivors (median $=4.00 ; \mathrm{IQR}=$ $0.00-10.00$ ). However, it is the most affected daily activities among the sandwich generation (middle age group).

Rest and sleep are important daily activities as it supports a healthy and active engagement in other activities (AOTA, 2014). Numerous studies (Burgard, Ailshire \& Hughes, 2010; Tsai \& Li, 2004; Liu et al., 2000; Latta et al., 2005; Groeger, Zijlstra \& Dijk, 2004 ) found that women had less sleep quality when compared to men, even though their sleep time is almost as similar to their male counterparts. This can be due to many factors such as taking care of children, care for others, and the fact that men indulge in leisure time more than women (Burgard, Ailshire \& Hughes, 2010). Thus, the needs and expectation of women to take care of the family and clean-up has an impact on women flood survivors rest and sleep.

It can be proposed that rest and sleep of the survivors will be disturbed, hence, making it among the most affected occupations. Several studies (Hamaoka et al., 2007; Ahmadizadeh et al., 2010; Dziwornu \& Kugbey, 2015; Othman, Dahlan, Borhani \& Rusdi, 2016), have stated that a flood can cause post-traumatic stress disorder (PTSD) among the survivors, which impacts on a myriad problems where sleep disturbances is one of them. Sleep disturbance may be due to fear of sleep, change in the living or sleeping environment, increased activity at night, and chronic pain due to a physical disorder (JCS and JCC Joint Working Group, 2015). JCS and JCC Joint Working Group (2015) further explains that sleep disturbances may include prolonged sleep latency, increase in the number of awakenings and wake time, and decreases the total sleep time or quality of sleep. However, the survivors in this study rate rest and sleep as the least affected occupations after a flood. According to Demiryi et al. (2015) survivors experienced a change in sleep patterns, which brings about a change in habits and the addition of new daily activities helped people cope with the situation. The value of daily activities, particularly collaborative ones, is an effective support for coping with a disaster and personal problems (Demiryi et al., 2015). The change in the pattern of occupations, where the survivors now focused more on cleaning up the house, cooperating, and sharing with the neighbours, had helped them overcome the problems they perceived regarding rest and sleep.

\subsection{I-FLOAT score on age group}

Table 3 illustrate the significant difference between the three age group (young adult, middle age, and elderly) for each domain on the I-FLOAT questionnaire. ADLs, IADLs, and rest and sleep, were found to be significant among middle age and elderly which is related to this study objective, in finding the most affected occupations among middle age group.

The Kruskal-Wallis Test revealed a statistically significant difference in engagement in ADL across the three different age groups (young adult, $n=57$ : 18-35 years old, middle adulthood, $n=34: 36-59$ years old, elderly, $n=40: \geq 60$ years old), $x 2(2.00, n=131)=$ $5.81, p=0.05$. The middle adulthood (36-59 years old) and elderly $(\geq 60$ years old) recorded a higher median score $(M d=7.00)$ than the young adult group, which recorded a median value of 6.00 .

Futhermore, the Kruskal-Wallis Test revealed a statistically significant difference in engagement in IADL across the three different age groups (young adult, $n=57$ : 18-35 years old, middle adulthood, $n=34: 36-59$ years old, elderly, $n=40: \geq 60$ years old), $x 2$ (2.00, $n=131)=11.58, p=0.00$. The middle adulthood (36-59 years old $)$ and elderly $(\geq 60$ years old $)$ recorded a higher median score $(\mathrm{Md}=$ $7.00)$ than the young adult group, which recorded a median value of 6.00 .

Rest and sleep revealed a statistically significant difference using the Kruskal-Wallis Test across the three different age groups (young adult, $n=57$ : 18-35 years old, middle adulthood, $n=34: 36-59$ years old, elderly, $n=40: \geq 60$ years old), $x 2(2.00, n=131)=$ $11.42, p=0.00$. The middle adulthood ( $36-59$ years old) and elderly $(\geq 60$ years old) recorded a higher median score $(M d=5.00)$ than the young adult group, which recorded a median value of 4.00 .

Education, play, leisure, and overall level of difficulty were found to be significant with young adult, whereas, work and social participation did not have significant differences when checked with the age group. 
Engagement in education across the three different age groups (young adult, $n=40: 18-35$ years old, middle adulthood, $n=9$ : 3659 years old, elderly, $n=7$ : $\geq 60$ years old), $x 2(2.00, n=56)=8.87, p=0.01$, revealed a statistically significant difference by using the Kruskal-Wallis Test. The young adult (18-35 years old) recorded a higher median score (Md $=6.00)$ than the middle adulthood group, which recorded a median value of 3.00 .

The Kruskal-Wallis Test revealed a statistically significant difference in engagement in play across the three different age groups (young adult, $n=37$ : 18-35 years old, middle adulthood, $n=17: 36-59$ years old, elderly, $n=25: \geq 60$ years old), $x 2(2.00, n=79)=$ $71.06, p=0.00$. The young adult (18-35) group recorded a higher median score ( $M d=6.00)$ than the middle adulthood and elderly group, which recorded a median value of 5.00 .

Moreover, leisure was found to revealed a statistically significant difference using the Kruskal-Wallis Test across the three different age groups (young adult, $n=57: 18-35$ years old, middle adulthood, $n=34: 36-59$ years old, elderly, $n=38: \geq 60$ years old), $x 2$ (2.00, $n=129)=21.41, p=0.00$. The young adult $(18-35)$ recorded a higher median score $(M d=6.00)$ than the middle adulthood and elderly group, which recorded a median value of 5.00 .

Lastly, the overall level of difficulty in engaging in occupations across three different age groups (young adult, $n=57$ : 18-35 years old, middle adulthood, $n=34$ : 36-59 years old, elderly, $n=40: \geq 60$ years old $), x 2(2.00, n=131)=12.01, p=0.00$ was also found to be statistically significant through the Kruskal-Wallis Test. The younger age group (18-35 years old) recorded a higher median score $(M d=60.00)$ than the other two age groups, which both recorded median value of 58.33 .

\begin{tabular}{|c|c|c|c|c|c|c|}
\hline Variables & $\begin{array}{l}\text { Demographic } \\
\text { Variables (Age) }\end{array}$ & $\mathrm{n}$ & median (IQR) & df & $x^{2}$ & p-value \\
\hline \multirow[t]{3}{*}{$\overline{A D L}$} & Young Adult (18-35) & 57 & $6.00(5.00-8.00)$ & & & \\
\hline & Middle Age (36-59) & 34 & $7.00(5.00-7.00)$ & 2.00 & 5.81 & 0.05 \\
\hline & Elderly $(\geq 60)$ & 40 & $7.00(7.00-8.00)$ & & & \\
\hline \multirow[t]{3}{*}{ IADL } & Young Adult (18-35) & 57 & $6.00(5.00-7.00)$ & & & \\
\hline & Middle Age (36-59) & 34 & $7.00(6.00-7.00)$ & 2.00 & 11.58 & 0.00 \\
\hline & Elderly $(\geq 60)$ & 40 & $7.00(7.00-8.00)$ & & & \\
\hline \multirow[t]{3}{*}{ Rest \& Sleep } & Young Adult (18-35) & 57 & $4.00(4.00-4.00)$ & & & \\
\hline & Middle Age (36-59) & 34 & $5.00(5.00-7.00)$ & 2.00 & 11.42 & 0.00 \\
\hline & Elderly $(\geq 60)$ & 40 & $5.00(4.00-5.00)$ & & & \\
\hline \multirow[t]{3}{*}{ Education } & Young Adult (18-35) & 40 & $6.00(6.00-7.00)$ & & & \\
\hline & Middle Age (36-59) & 9 & $3.00(0.00-5.50)$ & 2.00 & 8.87 & 0.01 \\
\hline & Elderly $(\geq 60)$ & 7 & $5.00(0.00-6.00)$ & & & \\
\hline \multirow[t]{3}{*}{ Work } & Young Adult (18-35) & 36 & $7.00(7.00-8.00)$ & & & \\
\hline & Middle Age (36-59) & 9 & $4.00(0.00-7.50)$ & 2.00 & 3.32 & 0.19 \\
\hline & Elderly $(\geq 60)$ & 3 & $7.00(0.00-)$. & & & \\
\hline \multirow[t]{3}{*}{ Play } & Young Adult (18-35) & 37 & $6.00(6.00-6.00)$ & & & \\
\hline & Middle Age (36-59) & 17 & $5.00(5.00-5.00)$ & 2.00 & 71.06 & 0.00 \\
\hline & Elderly $(\geq 60)$ & 25 & $5.00(3.00-5.00)$ & & & \\
\hline \multirow[t]{3}{*}{ Leisure } & Young Adult (18-35) & 57 & $6.00(6.00-6.00)$ & & & \\
\hline & Middle Age (36-59) & 34 & $5.00(4.75-5.25)$ & 2.00 & 21.41 & 0.00 \\
\hline & Elderly $(\geq 60)$ & 38 & $5.00(4.75-5.00)$ & & & \\
\hline \multirow[t]{3}{*}{ Social Participation } & Young Adult (18-35) & 57 & $6.00(5.00-7.00)$ & & & \\
\hline & Middle Age (36-59) & 34 & $6.00(3.00-6.00)$ & 2.00 & 2.54 & 0.28 \\
\hline & Elderly $(\geq 60)$ & 40 & $6.00(5.00-6.00)$ & & & \\
\hline \multirow[t]{3}{*}{ Overall Level of Difficulty } & Young Adult (18-35) & 57 & $60.00(57.14-62.68)$ & & & \\
\hline & Middle Age (36-59) & 34 & $58.33(50.84-60.00)$ & 2.00 & 12.01 & 0.00 \\
\hline & Elderly $(\geq 60)$ & 40 & $58.33(54.07-58.33)$ & & & \\
\hline
\end{tabular}

Further posthoc analysis was done for the ADL, IADL, and rest and sleep domains, to identify domains that the sandwich generation (middle age) are having difficulties in performing. Based on table 4, it was found that rest and sleep to have a significant difference with the middle age group. A post hoc test using the Mann-Whitney $U$ Test revealed a statistically significant difference in engagement in rest and sleep with the middle adulthood group having a higher mean rank ( $M=43.53, n=34)$ and the elderly have a lower mean rank $(M=32.38, n=40), U=475.00, z=-2.37, p=0.02, r=0.28$. ADL and IADL were found to show significant difference with the elderly group.

Table 4. Post Hoc test to determine significant difference in middle age group

\begin{tabular}{llllllll}
\hline Variables & $\begin{array}{l}\text { Demographic } \\
\text { Variables (Age) }\end{array}$ & $\mathbf{n}$ & median (IQR) & $\begin{array}{c}\text { Mean } \\
\text { Rank }\end{array}$ & U & Z-score & p-value \\
\hline ADL & Middle Age (36-59) & 34 & $7.00(5.00-7.00)$ & 32.22 & 500.50 & -2.09 & 0.04 \\
& Elderly $(\geq 60)$ & 40 & $7.00(7.00-8.00)$ & 41.99 & & & \\
IADL & Middle Age (36-59) & 34 & $7.00(6.00-7.00)$ & 32.68 & 516.00 & -1.90 & 0.05 \\
& Elderly ( $\geq 60)$ & 40 & $7.00(7.00-8.00)$ & 41.60 & & & \\
Rest and Sleep & Middle Age (36-59) & 34 & $5.00(5.00-7.00)$ & 43.53 & 475.00 & -2.37 & 0.02 \\
& Elderly ( $\geq 60)$ & 40 & $5.00(4.00-5.00)$ & 32.38 & & & \\
\hline
\end{tabular}

Mann-Whitney $U$ Test. IQR = interquartile range; $n=$ number of participants; $U=U$ statistics; $p$-value $<0.05$ 


\subsection{Relationship between difficulty in engaging in rest and sleep with other demographic variables}

\begin{tabular}{|c|c|c|c|c|c|c|}
\hline $\begin{array}{l}\text { Demographic } \\
\text { Variables }\end{array}$ & $\begin{array}{l}\text { Demographic } \\
\text { Variables (Age) }\end{array}$ & $\mathrm{n}$ & median (IQR) & df & $x^{2}$ & $\mathrm{p}$-value \\
\hline \multirow[t]{2}{*}{ No. Of Health Problem } & No Illness & 71 & $4.00(4.00-7.00)$ & \multirow{3}{*}{2.00} & \multirow{3}{*}{7.37} & \multirow{3}{*}{0.02} \\
\hline & $\begin{array}{l}1-2 \text { Illnesses } \\
3-5 \text { Ilnesses }\end{array}$ & $\begin{array}{l}16 \\
44\end{array}$ & $5.00(4.00-6.00)$ & & & \\
\hline \multirow{4}{*}{ Marital Status } & Married & 62 & $5.00(5.00-5.00)$ & & & \\
\hline & Sinale & 40 & & \multirow{3}{*}{3.00} & \multirow{3}{*}{6.57} & \multirow{3}{*}{0.08} \\
\hline & Divorce & 9 & $4.00(4.00-4.00)$ & & & \\
\hline & Widow & 20 & $5.00(4.00-5.75)$ & & & \\
\hline \multirow{3}{*}{ No. of Children } & $0-1$ & 30 & $5.00(4.00-7.00)$ & \multirow{3}{*}{2.00} & \multirow{4}{*}{0.10} & \multirow{3}{*}{0.95} \\
\hline & $2-4$ & 41 & $5.00(4.00-6.00)$ & & & \\
\hline & $5-10$ & 34 & $5.00(4.00-5.25)$ & & & \\
\hline No. of Person Living & $0-3$ & 35 & $4.00(4.00-5.00)$ & & & \\
\hline \multirow[t]{2}{*}{ Together } & $4-5$ & 36 & $4.00(4.00-4.00)$ & \multirow[t]{2}{*}{2.00} & \multirow[t]{2}{*}{18.85} & \multirow[t]{2}{*}{0.00} \\
\hline & $6-11$ & 60 & $5.00(5.00-5.00)$ & & & \\
\hline \multirow[t]{4}{*}{ Educational Background } & Primary School & 25 & $4.00(4.00-6.00)$ & \multirow{4}{*}{3.00} & \multirow{4}{*}{8.91} & \multirow{4}{*}{0.03} \\
\hline & Secondary School & 32 & $4.00(3.00-7.00)$ & & & \\
\hline & University/College & 34 & $4.00(4.00-4.00)$ & & & \\
\hline & Others & 40 & $5.00(5.00-5.00)$ & & & \\
\hline \multirow[t]{5}{*}{ Total Number of Flood } & $0-2$ times & 28 & $6.50(3.00-9.75)$ & \multirow{5}{*}{2.00} & \multirow{5}{*}{13.39} & \multirow{5}{*}{0.00} \\
\hline & $3-4$ times & 42 & $4.00(4.00-4.00)$ & & & \\
\hline & $5-11$ times & 61 & $5.00(4.00-5.00)$ & & & \\
\hline & Middle Age (36-59) & 34 & $58.33(50.84-60.00)$ & & & \\
\hline & Elderly $(\geq 60)$ & 40 & $58.33(54.07-58.33)$ & & & \\
\hline
\end{tabular}

Table 5 shows the relationship between difficulty in engaging in rest and sleep with other demographic variables. The KruskalWallis Test revealed a statistically significant difference in engagement in Rest and Sleep with the grouping of number of health problems (no illness, $n=71,1-2$ illness, $n=16,3-5$ illness, $n=44), x 2(2.00, n=131)=7.37, p=0.02$. The 1-2 and 3-5 illnesses group recorded a higher median score $(M d=5.00)$ than the other group, with the group of no illness having the lowest median value of 4.00 .

Sleep serves as a restorative function for the human body which benefits the physical, physiological, neurobehavioral and neurocognitive functioning (Assefa, Diaz-Abad, Wickwire \& Scharf, 2015). Not having enough sleep among flood disaster survivors, impaired these restorative functions. To make matters worse, they already have pre-existing medical conditions such as cardiac problems, high blood pressure, and diabetes, that alter the body functions and have been known to cause sleep problems to its sufferers (JCS and JCC Joint Working Group, 2015; Li et al., 2015; lyer, 2012). Despite their medical conditions, they still need to focus all their energy on taking care of others and ultimately cleaning up the house. This, in turn, gives them little rest and used more energy, where in respect of their conditions, they should focus on restorative instead. If the situation persists, it can be a threat to the overall health of the survivors with existing medical conditions. All these factors explain why middle age survivors with illnesses had experienced more difficulty in engaging in rest and sleep activities.

Moreover, the Kruskal-Wallis Test revealed a statistically significant difference in engagement in Rest and Sleep with total number of flood experienced (0-2 times, $n=28,3-4$ times, $n=42,5-11$ times, $n=61), x 2(2.00, n=131)=13.39, p=0.00$. The group with least exposure to flood $(0-2$ times) recorded a higher median score $(M d=6.50)$ than the other groups, with 5-11 number of flood experienced having the lowest median value of 4.00 .

Those who experienced flood from 0 - 2 times, had difficulty with rest and sleep, most probably due to the survivors developing PTSD, as they still haven't developed the resilience to face a flood and cope with the situation. According to Ahmed (2007), resilience is the ability to use various methods such as beliefs, attitude, and coping strategies to maintain a state of normalcy in facing unfavourable circumstances. The absence of resilience makes the survivors more vulnerable to stress, hence, developing PTSD (Lebens \& Lauth, 2016). As mentioned earlier, the development of PTSD among the survivors had caused disturbances in the sleep pattern and quality of the survivors (Ahmadizadeh et al., 2010; Tempesta et al., 2013; Dziwornu \& Kugbey, 2015). Thus, explains why the survivors who are experiencing $0-2$ times of flood experienced more sleep difficulties.

Furthermore, the Kruskal-Wallis Test revealed a statistically significant difference in engagement in Rest and Sleep with the number of persons living together (0-3 person living together, $n=35,4-5$ person living together, $n=36,6-11$ person living together, $n$ $=60), x 2(2.00, n=131)=18.85, p=0.00$. The most number of persons living together $(6-11)$ group recorded a higher median score $(M d=5.00)$ than the other groups, with 0-3 and 4-5 number of person living together having the lowest median value of 4.00 .

Lastly, there is a statistically significant difference in engagement in Rest and Sleep with educational background (primary school, $n$ $=25$, secondary school, $n=32$, university/college, $n=34$, others, $n=40), x 2(3.00, n=131)=8.91, p=0.03$ using the Kruskal-Wallis Test. The other educational background group recorded a higher median score $(M d=5.00)$ than the other groups, with primary school, secondary school, and university/college education background having the lowest median value of 4.00 . 
Table 6. Relationship between difficulty in engaging in rest and sleep with other demographic variables

\begin{tabular}{llcccccc}
\hline Variables & $\begin{array}{l}\text { Demographic } \\
\text { Variables (Age) }\end{array}$ & $\mathbf{n}$ & median (IQR) & $\begin{array}{l}\text { Mean } \\
\text { Rank }\end{array}$ & $\mathbf{U}$ & Z-score & p-value \\
\hline No. of Health & $1-2$ lllnesses & 16 & $5.00(4.00-6.00)$ & 29.56 & 337.00 & -0.28 & 0.78 \\
Problem & $3-5$ Illnesses & 44 & $5.00(5.00-5.00)$ & 30.84 & & & \\
Employment & Employed & 55 & $4.00(4.00-4.00)$ & 50.66 & 1246.50 & -4.10 & 0.00 \\
Status & Unemployed & 76 & $5.00(4.00-5.75)$ & 77.10 & & &
\end{tabular}

Mann-Whitney $U$ Test. IQR = interquartile range; $n=$ number of participants; $U=U$ statistics; $p$-value $<0.05$

Further posthoc analysis done for number of health problem (table 6), didn't find significant difference between $1-2$ or $3-5$ illnesses for engagement in rest and sleep. Thus, imply those with illnesses were to be affected with rest and sleep activity.

Based on table 6, it was also found that employment status were statistically significant with engagement in rest and sleep. The Mann-Whitney $U$ Test revealed a significant difference in the engagement in rest and sleep with the employed having a lower median rating $(M d=4.00, n=55)$ and unemployed with a higher median rating $(M d=5.00, n=76), U=1246.50, z=-4.10, p=0.00, r=0.36$.

The difficulty in rest and sleep among survivors in their middle age (36 - 59 years old), is most probably because they are the sandwich generation that needs to take care of both the children/young adults and the elderly. Parker and Patten (2013), state that the sandwich generation is responsible for the financial support of young adults (18 and above), and care for the young child and their parents. The sandwich generation is facing the pressure and stress to help others they care about, while still pursuing their interests and daily activities to achieve personal balance (Allen \& Stearns, 2014; Marts, 2013). Besides being the primary caregiver, taking care of everyone (both young and the elderly), is the precipitating factors that was found in this study, as to why the survivors had more problems in rest and sleep because they had to take care of 6 - 11 people living together in the house, had others (did not complete their school) education background, and is unemployed. Since they are not working, all these factors put more pressure on the survivors (who belong to the sandwich generation) to work more in cleaning up the house (household maintenance), whilst, taking care (meals preparation, care of others, and child rearing) of others ( $6-11$ other people) in the household.

Not being able to engage in rest and sleep activities, which is part of daily activities, creates an imbalance in their daily routine. This imbalance will affect the survivor's health (physically and mentally), which in turn will affect their quality of life. This is supported by AOTA (2014), where the outcome of health, wellness, well-being, and quality of life is achieved when there is balance in their performance in daily activities. Quality of life is the perception of progress towards goals, hope, self-concept, health and functioning (AOTA, 2014). Thus, it is imperative that the quality of life among the survivors be maintained and improved, through the promotion of engagement and balance daily activities for them to be able to get back on their feet post-disaster, rebuilding their life and the community faster, hence, lessen the impact of a flood disaster. Since the middle age flood survivors are having more problem with rest and sleep, the related agencies can provide more volunteer support to help them with other aspects of daily living, so that they would get enough rest and sleep.

\subsection{Conclusion}

In conclusion, it was found that rest and sleep were affected among those who are in their middle age (36 - 59 years old), those with illness, had a huge number of people living together (6-11), other education background, an experience of flood $0-2$ times, and is unemployed. Despite ADLs, IADLs, and work is the most affected occupations, and rest and sleep the least affected, they shared almost similar issues. Women, regardless of their background, suffered a lot during a disaster, as, in addition to take care of their self, they need to take care of the whole family. The social construct built around women made them responsible for domestic duties. Hence, making their hands full, juggling everything, making work-life-leisure balance hard in times of disaster. This imbalance in the pattern of women occupation during a disaster caused an occupational imbalance that impacts a person health, wellness, well-being, and quality of life. When all these are affected, developing resilience of the survivors can be hard and fruitless even with all the campaign and programs done by the government and NGOs. Thus, the findings in this study can be used to ease the problem faced by women in times of a disaster, so that a more resilient community towards a disaster can be developed. Recommendations can be made by getting a data on occupational engagement among Malaysian populations. This is crucial so that we can compare the performance of the survivors during disaster to the overall occupational engagement of Malaysian, so it would serve as a baseline that is locally appropriate, being able to measure the impact of flood disaster on its' survivors everyday activities.

\section{Acknowledgements}

The authors wish to thank Faculty of Health Sciences, University Teknologi MARA (UiTM) for permission to conduct the study and to all participants in the study.

\section{References}

Abdullah, S., Sipon, S., Nazli, N. N. N. N., \& Puwasa, N. H. (2015). The relationship between stress and social support among flood victims. Procedia-Social and Behavioral Sciences, 192, 59-64. 
Ahmadizadeh, M. J., Ahmadi, K., Eskandari, H., Falsafinejad, M. R., Borjali, A., Anisi, J., \& Teimoori, M. (2010). Improvement in quality of life after exposure therapy, problem solving and combined therapy in chronic war-related post traumatic stress disorder. Procedia - Social and Behavioral Sciences, 5(2), 262-266. doi:10.1016/j.sbspro.2010.07.085

Ahmed, A. S. (2007). Post-traumatic stress disorder, resilience and vulnerability. Advances in Psychiatric Treatment, 13(5), 369-375.

Ajibade, I., McBean, G., \& Bezner-Kerr, R. (2013). Urban flooding in Lagos, Nigeria: Patterns of vulnerability and resilience among women. Global Environmental Change, 23(6), 1714-1725.

Akasah, Z. A., \& Doraisamy, S. V. (2015). 2014 Malaysia flood: impacts \& factors contributing towards the restoration of damages. Journal of Scientific Research and Development, 2(14), 53-59. Retrieved from http://jsrad.org/wp-content/2015//ssue\%2014,\%202015/9jj.pdf

Allen, S., \& Stearns, D. (2014). Caught in the middle: how does the sandwich generation woman not get squezzed? Family Wealth Advisor Council.

American Occupational Therapy Association. (2014). Occupational therapy practice framework: Domain \& process $3^{\text {rd }}$ Edition. Amer Occupational Therapy Assn. Assefa, S. Z., Diaz-Abad, M., Wickwire, E. M., \& Scharf, S. M. (2015). The functions of sleep. AIMS Neuroscience, 2(3), 155-171.

Baker, S. B. (2012). Occupational therapists in disaster preparedness, response, and recovery : a survey of knowledge and attitudes [Doctoral Project]. The University of Toledo. Retrieved from http://utdr.utoledo.edu/cgi/viewcontent.cgi?article=1140\&context=graduate-projects

Burgard, S., Ailshire, J. A., \& Hughes, N. M. (2010). Gender and sleep duration among American adults. Ann Arbor, Ml: Population Studies Center, University of Michigan.

Demiryi, M. M., Boggio, C., Boffelli, M., Chiapessoni, D., Demichelis, M., \& Heit, M. C. (2015). Listening to the voices of survivors: the floods of 2003 in santa fe, argentina. In N. Rushdord \& K. Thomas (Eds.), Disaster and development: an occupational perspective (p. 53). Ediburgh, UK: Elsevier Ltd.

Dziwornu, E., \& Kugbey, N. (2015). Mental Health Problems and Coping among Flood Survivors in Ghana: A Comparative Study of Survivors and Non-Survivors. Current Research in Psychology, 6(1), 15.

Fine, S. B. (1991). Resilience and human adaptability: Who rises above adversity?. American Journal of Occupational Therapy, 45(6), 493-503.

Groeger, J. A., Zijlstra, F. R. H., \& Dijk, D. J. (2004). Sleep quantity, sleep difficulties and their perceived consequences in a representative sample of some 2000 British adults. Journal of sleep research, 13(4), 359-371.

Hamaoka, D. A., Benedek, D. M., \& Grieger, T. A. (2007). Crisis intervention. In G. Fink (Ed.), Encylopedia of stress (2nd ed., p. 662). Oxford, UK: Elsevier, Inc.

Heshmati, R., Hoseinifar, J., Rezaeinejad, S., \& Miri, M. (2010). Sensation seeking and marital adjustment in handicapped veterans suffering from PTSD. ProcediaSocial and Behavioral Sciences, 5, 1783-1787.

lyer, S. R. (2012). Sleep and type 2 diabetes mellitus-clinical implications. JAPI, 60, 43

JCS, J., \& JCC Joint Working Group. (2015). Guidelines for Disaster Medicine for Patients With Cardiovascular Diseases (JCS 2014/JSH 2014/JCC 2014)-Digest Version-. Circulation Journal, 80(1), 261-284.

Latta, F., Leproult, R., Tasali, E., Hofmann, E., \& Van Cauter, E. (2005). Sex differences in delta and alpha EEG activities in healthy older adults. Sleep, 28(12), 15251534.

Lebens, M. L., \& Lauth, G. W. (2016). Risk and Resilience Factors of Post-Traumatic Stress Disorder: A Review of Current Research. Clin Exp Psychol, 2(120), 2.

Li, Y., Vgontzas, A. N., Fernandez-Mendoza, J., Bixler, E. O., Sun, Y., Zhou, J., ... \& Tang, X. (2015). Insomnia With Physiological Hyperarousal Is Associated With Hypertension Novelty and Significance. Hypertension, 65(3), 644-650.

Liu, X., Uchiyama, M., Kim, K., Okawa, M., Shibui, K., Kudo, Y., ... \& Ogihara, R. (2000). Sleep loss and daytime sleepiness in the general adult population of Japan. Psychiatry Research, 93(1), 1-11.

Marts, S. Z. (2013). Sandwich Generation Caregivers: Ethical Legacies Throughout Generations (Doctoral Dissertation). University of San Fransisco.

Mohit, M. A., \& Sellu, G. M. (2013). Mitigation of climate change effects through non-structural flood disaster management in Pekan Town, Malaysia. Procedia-Social and Behavioral Sciences, 85, 564-573.

Neumayer, E., \& Plümper, T. (2007). The gendered nature of natural disasters: The impact of catastrophic events on the gender gap in life expectancy, 1981-2002. Annals of the Association of American Geographers, 97(3), 551-566.

Oakley, F., Caswell, S., \& Parks, R. (2008). The Issue Is... Occupational Therapists' Role on US Army and US Public Health Service Commissioned Corps Disaster Mental Health Response Teams. The American journal of occupational therapy: official publication of the American Occupational Therapy Association, 62(3), 361.

Othman, A. Z., Dahlan, A., Borhani, S. N., \& Rusdi, H. (2016). Posttraumatic Stress Disorder and Quality of Life among Flood Disaster Victims. Procedia-Social and Behavioral Sciences, 234, 125-134.

Parker, K., \& Patten, E. (2013). The sandwich generation: Rising financial burdens for middle-aged Americans. Pew Research Center, Social \& Demographic Trends Project.

Reyes, D. D., \& Lu, J. L. (2015). Gender dimension in disaster situations: A case study of flood prone women in Malabon City, Metro Manila. International Journal of Disaster Risk Reduction.

Riggers, L. (2011). Healing Haiti: The experience of an Occupational Therapist in disaster response. 
Scaffa, M. E., Gerardi, S., Herzberg, G., \& McColl, M. A. (2009). The role of occupational therapy in disaster preparedness, response, and recovery. The American Journal of Occupational Therapy: Official Publication of the American Occupational Therapy Association, 60(6), 642-9. Retrieved from http://www.ncbi.nlm.nih.gov/pubmed/17153569

Srivastava, A. K., David, M. R., \& Ramakrishnan, P. (2006). The disasters in India and occupational therapy response. The Indian Journal of Occupational Therapy,37(3)

Stone, G. V. (2006). Occupational therapy in times of disaster. American Journal of Occupational Therapy, 60(1), 7-8.

Tempesta, D., Curcio, G., De Gennaro, L., \& Ferrara, M. (2013). Long-term impact of earthquakes on sleep quality. PLoS One, 8(2), e55936.

Townsend, E.A., \& Whiteford, G. (2005). A participatory occupational justice framework: Population-based processes of practice. In F. Kronenberg, S.S. Alagado, \& N. Pollard (Eds), Occupational Therapy without borders: Learning from the spirit of survivors. Toronto, ON: Elsevier Churchill Livingstone.

Rosenfeld, M. S. (1989). Occupational disruption and adaptation: A study of house fire survivors. American Journal of Occupational Therapy, 43(2), 89-96.

Tsai, L. L., \& Li, S. P. (2004). Sleep patterns in college students: Gender and grade differences. Journal of psychosomatic research, 56(2), 231-237.

United Nations Development Programme. (2010). Gender and disasters. Retrieved http://www.undp.org/content/dam/undp/library/crisis\%20prevention/disaster/7Disaster\%20Risk\%20Reduction\%20-\%20Gender.pdf

Zokaeefar, A., Mirbeigi, S., Eskash, H., Dousti, M., Sedaghatpishe, A., \& Shafii, H. (2015). Assessment of counseling and psychosocial support maneuvers in natural disasters in hormozgan. Procedia - Social and Behavioral Sciences, 185, 35-41. doi:10.1016/j.sbspro.2015.03.429 